\title{
A pressure-actuated open-field apparatus for rodents
}

\author{
JOHN J. PORTER, JOHN J. HUDY, and ANN M. FURBER \\ University of Wisconsin, Milwaukee, Wisconsin 53201
}

\begin{abstract}
An open-field grid test device is described that consists of a series of "electrical grating" contact switches mounted beneath a flexible Plexiglas field. Detection of movement occurs when the weight of the subject depresses the Plexiglas and closes one of the underlying switches. Calibration procedures and sources of supply for constructing the grids are described.
\end{abstract}

The use of the open field as a test of emotional or motivational state has a long history (cf. Hall, 1934) In the past few years, the characteristics of the open field and the types of data obtained from the open field have undergone considerable scrutiny (Archer, 1973; Denenberg, 1969; Royce, 1977; Walsh \& Cummins, 1976). The apparatus described here permits the automatic recording of rodent locomotion without the presence of an observer. Unlike previous methods of automating open-field observations (cf. Morgret \& Albee, 1974; Pfister, Mudge, \& Harcombe, 1978), this unit uses no electronic circuitry, is immune to the conductive effects of rodent urine, and can readily be adjusted to accommodate differences in weight between animals.

\section{APPARATUS}

Animal activity was detected by closure of "electrical grating" touch-activated switches beneath a thin, flexible Plexiglas sheet. As the animal moved over the Plexiglas sheet, causing deflection of the $.08-\mathrm{cm}$-thick sheet, the normally open switches closed, activating a $28-\mathrm{V}$ circuit and counter. The switches, Model TC-1C from Refac Electronics, ${ }^{1}$ changed from normally open to closed with a vertical deflection of $.12 \mathrm{~mm}$. These switches are typical of units used in many touch switch applications and should be available from several vendors in any large city. Blocks of flexible expanded polyurethane foam, 1 to $1.2 \mathrm{~cm}$ thick, were used to support the Plexiglas sheeting and as a means of adjusting switch sensitivity through variations in the polyurethane block thickness. Figure 1 de tails the moun ting of the switches, the polyurethane supports, and the Plexiglas floor of the open-field cages.

The open fields were constructed on a $65 \times 65 \mathrm{~cm}$ particle-board base $1.9 \mathrm{~cm}$ thick. The central $60 \times 60 \mathrm{~cm}$ floor area was divided into $1615-\mathrm{cm}$ squares, and nine polyurethane supports were placed in a $15-\mathrm{cm}^{2}$ grid configuration, as shown in Figure 2. The flexible Plexiglas floor of the field was suspended from the perimeter of the field by means of $2.5 \times 1.5 \mathrm{~cm}$ (width $\mathrm{x}$ height) plywood strips, as shown in Figure 2.
The cage walls and ceiling were constructed of $.6-\mathrm{cm}$ galvanized screening, supported by $2.5-\mathrm{cm}$ pine square stock. The entire cage-screening assembly was designed to rest upon the switch-floor assembly in such

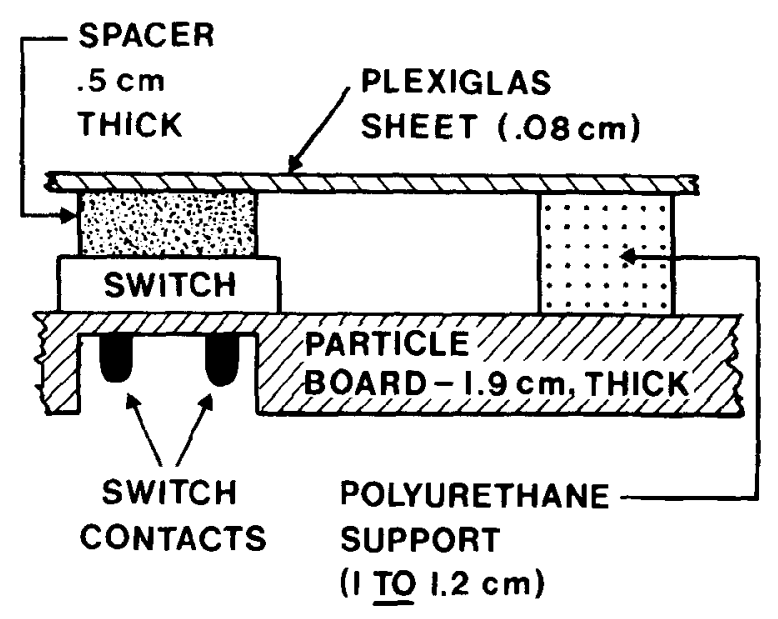

FIGURE I

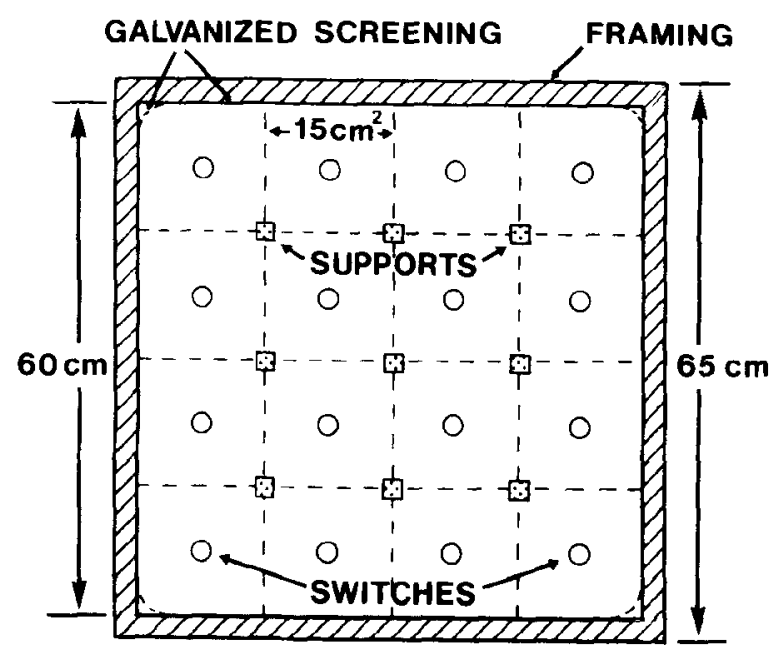

FIGURE 2 
fashion that it could be removed readily for cleaning of the Plexiglas floor. In turn, the Plexiglas floor was not fastened to the perimeter. Finally, the corners of the galvanized screening walls were radiused in order to prevent animals from chewing on the pine framing.

Calibration of the grids is sensitive to the density and thickness of the polyurethane foam that is used. The material used here (obtained as packing with TTL logic chips), when of $1-$ to $1.2-\mathrm{cm}$ thickness, generated consistent single switch closures to a static $300-\mathrm{g}$ weight placed within $5 \mathrm{~cm}$ of the switches. Calibrated to these criteria, observations of animals in the grids has indicated reliable switch closures when animals weighing from 300 to $600 \mathrm{~g}$ move about the grids. This calibration has held at the periphery, as well as in the center of the fields. In all of our observations, movement resulted in the closure of only one switch; the latter probably resulted from the tendency of the floor to bulge upward in one section when it was depressed in another.

These open fields have been used for more than 1 year, averaging $12 \mathrm{~h} /$ day, and have proved completely trouble free. The only potential difficulty is in the use of cleaning agents that either dissolve the Plexiglas or reduce its flexibility and thus its sensitivity to movement. We have found that ordinary tap water and a mild soap solution are more than sufficient for cleaning purposes.

\section{REFERENCES}

ARCher, J. Tests for emotionality in rats and mice: A review. Animal Behavior, 1973, 21, 205-235.

DENENBERG, V. H. Open-field behavior in the rat: What does it mean. Annals of New York Academy of Sciences, 1969, 159, 852-859.

Hall, C. S. Emotional behavior in the rat: Defecation and urination as a measure of individual differences in emotionality. Journal of Comparative Psychology, 1934, 18, 385-403.

Morgret, M. K., \& AlbeE, P. R. An automated open-field apparatus utilizing an improved resistance detection circuit. Behavior Research Methods \& Instrumentation, 1974, 6, 327-328.

Prister, H. P., Mudge, R. R., \& Harcombe, A. O. A multipurpose activity platform utilized in the open-field setting. Behavior Research Methods \& Instrumentation, 1978, 10, 21-22.

RoYce, J. R. On the construct validity of open-field measures. Psychological Bulletin, 1977, 84, 1098-1106.

Walsh, R. N., \& Cummins, R. A. The open-field test: A critical review. Psychological Bulletin, 1976, 83, 482-504.

\section{NOTE}

1. Available as WILD ROVER TC-1/C switches. These were available for approximately 60 cents each at the time of writing from REFAC Electronics Corporation, P.O. Box 809, Winsted, Connecticut 06098 [phone: (203) 379-2731].

(Received for publication February 2, 1978; revision accepted December 28, 1978.) 